\title{
Faktor-Faktor yang Mempengaruhi Pengguna Gojek menggunakan Gopay
}

\section{Factors that Influence Gojek Users to utilize Gopay}

\author{
Tiar Lina Situngkir ${ }^{1)}$, Ratih Hurriyati ${ }^{2)}$, Mokh. Adib Sultan ${ }^{3)}$ \\ ${ }^{1)}$ Fakultas Ekonomi dan Bisnis, Universitas Singaperbangsa, Karawang \\ ${ }^{2,3)}$ Sekolah Pasca Sarjana, Universitas Pendidikan Indonesia, Bandung \\ e-mail korespondensi: tiarlina.situngkir@fe.uniska.ac.id
}

\begin{tabular}{|l|}
\hline Info Artikel \\
\hline Riwayat Artikel : \\
Diterima: 17 Desember 2019 \\
Disetujui: 05 Januari 2020 \\
Dipublikasikan: Januari 2020 \\
\hline Nomor DOI \\
10.33059/jseb.v11i1.1998 \\
Cara Mensitasi : \\
Situngkir, T.L., Hurriyati, R. \\
\& Sultan, M.A. 2020. Faktor- \\
Faktor yang Mempengaruhi \\
Pengguna Gojek menggunakan \\
Gopay. Jurnal Samudra \\
Ekonomi dan Bisnis. 11(1): \\
111-121.
\end{tabular}

111-121.

\begin{abstract}
Abstrak
Penelitian ini bertujuan menganalisa faktor-faktor yang mempengaruhi pelanggan Gojek menggunakan layanan Gopay. Populasinya adalah civitas Universitas Singaperbangsa, Karawang yang secara aktif menggunakan Gojek dan layanan Gopay yang jumlahnya tidak diketahui secara jelas. Sampel diambil untuk dianalisa, dari pengisian kuisioner sebanyak-banyaknya diterima 118 respoden. Metode analisa regresi berganda yang diwakili oleh variabel bebas terdiri dari manfaat dan biaya keuangan. Hasil analisa membuktikan hanya variabel manfaat yang berpengaruh signifikan terhadap penggunaan Gojek memakai layanan Gopay; sementara variabel lainnya yaitu biaya keuangan tidak signifikan memberikan pengaruh terhadap penggunaan layanan Gopay. Penelitian ini memiliki keterbatasan lokasi, yang bisa berdampak terhadap hasil penelitian. Untuk masa yang akan datang, para peneliti berikutnya bisa lebih meluaskan wilayah penelitian.
\end{abstract}

Kata Kunci: Gojek, Gopay, Manfaat, Biaya Keuangan.

\begin{tabular}{|l|}
\hline Article Info \\
\hline Article History : \\
Received: 17 December 2019 \\
Accepted: 05 January 2020 \\
Published: January 2020 \\
\hline DOI Number : \\
10.33059/jseb.v11i1.1998 \\
How to cite : \\
Situngkir, T.L., Hurriyati, R. \\
\& Sultan, M.A. 2020. Faktor- \\
Faktor yang Mempengaruhi \\
Pengguna Gojek menggunakan \\
Gopay. Jurnal Samudra \\
Ekonomi dan Bisnis. 11(1): \\
111-121.
\end{tabular}

\section{Abstract}

This study aims to analyze the factors that influence Gojek customers using Gopay services. The population is the community of Singaperbangsa University, Karawang who actively use Gojek and Gopay services whose numbers are not clearly known. Samples were taken for analysis, from filling out the questionnaire as many as 118 respondents were received. The multiple regression analysis method represented by the independent variable consists of financial costs and benefits. The results of the analysis prove that only the benefit variable has a significant effect on the use of Gojek using Gopay services, the other variable is that financial costs do not significantly influence the use of Gopay services. This study has limited location, which can have an impact on the results of the study. In the future, subsequent researchers can further expand the research area.

Keywords: Gojek, Gopay, Benefits, Financial Costs. 


\section{PENDAHULUAN}

Gojek sebagai perusahaan transportasi online semakin tumbuh pesat, dan sebagai alat pembayaran dari jasa yang disediakan, Gojek memberikan dua pilihan, yaitu menggunakan tunai ataupun non tunai (dengan cara menggunakan layanan Gopay). Gojek membuka layanan non tunai karena melihat ada potensi besar untuk memperluas perangkat pembayaran di masa akan datang (Teoh et al., 2013).

Teori yang menjelaskan faktor-faktor yang mempengaruhi perubahan perilaku pelanggan menggunakan pembayaran tunai menjadi nontunai atau e-payment semakin berkembang. Venkatesh et al. (2012) dalam proses pengembangan UTAUT memberi paparan tentang tipe teknologi yang mungkin mampu meraih hati pelanggan. Dalam hal ini diperlukan pengenalan, dan pemahaman untuk mendorong penerimaan yang bersifat berkelanjutan melalui pelatihan, pemasaran, dan lain-lain. Upaya ini diupayakan agar target pelanggan untuk mengaplikasikan teknologi baru bisa terpenuhi.

Fenomena ini mengindikasikan banyak faktor yang dinilai mempengaruhi pelanggan berubah haluan dari menggunakan tunai ke non tunai. Menurut Davis (1989) bahwa kemudahan dan manfaat sangat mempengaruhi keputusan pelanggan menggunakan pembayaran dengan non tunai. Pemaparan bahwa hubungan baik antara kepercayaan dan kesetiaan terhadap situs juga menginspirasi pelanggan mau beralih dan menggunakan layanan non tunai diperoleh dari penelitian Flavián dan Guinalíu (2006). Harapan agar terjadinya peralihan dari pembayaran dengan tunai secara manual menjadi menggunakan teknologi bisa tercapai dengan semaksimal mungkin karena investasi yang digelontorkan sangat besar bisa bermanfaat bagi pelanggan. Oleh karena itu, kredibilitas situs harus bisa dipertanggungjawabkan untuk tidak menge- cewakan pelanggan dan tetap setia dengan layanan tersebut (Wang et al., 2003).

Penelitian terdahulu mempertimbangkan beberapa faktor yang dianggap mempengaruhi pelanggan menggunakan informasi teknologi dalam pembayaran. Teoh et al. (2013) menyatakan faktor-faktor manfaat, kepercayaan, efikasi, kemudahan penggunaan dan keamanan, mempengaruhi, penggunaan e-payment. Dilanjutkan Hsiao et al. (2016) yang meneliti utilitas, motivasi, hedonik, pengaruh sosial mempengaruhi kontinuitas penggunaan atas aplikasi mobile. Persepsi manfaat, kemudahan, kredibilitas, efikasi, dan biaya keuangan menjadi pertimbangan perilaku seseorang untuk menggunakan mobile banking (Luarn \& Lin, 2005).

Riset ini menggunakan Unified Theory of Acceptance and Use of Technology (UTAUT) sebagai pedoman dasar dalam memberikan pertimbangan demi memperkuat seseorang untuk menggunakan layanan teknologi adalah didukung hasil penelitian terdahulu oleh Venkatesh et al. (2003) yang menyatakan bahwa performa ekspektasi, usaha ekspektasi, pengaruh sosial, fasilitas, mempengaruhi seseorang untuk menggunakan layanan berbasis teknologi.

\section{Manfaat dan Biaya Keuangan}

Variabel pertama yang dijelaskan pada penelitian ini adalah manfaat. Chou (2004) menemukan pengguna dapat menikmati manfaat bertransaksi online dengan biaya rendah. Eastin (2002) dalam penelitiannya memaparkan argumen bahwa keputusan seseorang mengadopsi teknologi e-payment yang terdiri dari empat kegiatan e-commerce (belanja online, perbankan, investasi dan sistem pembayaran elektronik) dipengaruhi oleh manfaat finansial dan kenyamanan dalam penggunaan yang mana menjadi faktor penentunya. Argumen ini sejalan dengan hasil penelitian Gerrard dan Cunningham (2003) 
yang memandang manfaat ekonomi biaya tetap saat melakukan transaksi online mempengaruhi tingkat adopsi pembayaran elektronik dalam kegiatan seseorang.

Beberapa penelitian lainnya menyatakan pemanfaatan teknologi e-payment akan lebih menarik diadopsi apabila pada saat transaksi tidak menambahkan biaya lainnya selain tagihan yang harus diselesaikan (Gerrard \& Cunningham, 2003; San-Martin et al., 2012; San-Martin \& López-Catalán, 2013). Selain itu, Chakravorti (2003), menambahkan bahwa manfaat utama yang menarik di dalam pengunaan e-payment adalah hemat waktu dan biaya yang dirasakan pelanggan.

Berdasarkan beberapa argumen yang dimunculkan dari hasil-hasil penelitian terdahulu tersebut, maka hipotesis pertama yang diajukan dalam penelitian ini dikaitkan dengan keputusan pengguna Gojek untuk menggunakan fasilitas e-payment berupa Gopay adalah:

H1 : Terdapat pengaruh parsial secara signifikan dari manfaat yang dirasakan pengguna Gojek terhadap keputusannya menggunakan Gopay.

Biaya keuangan menurut Mathieson et al. (2001) adalah variabel yang dapat dapat mempengaruhi perilaku dan niat konsumen untuk menggunakan sitem e-payment. Biaya keuangan dipersepsikan penggunaan fasilitas e-payment membutuhkan uang. Sumber daya keuangan perseptif juga ditemukan sebagai anteseden yang signifikan dari niat untuk menggunakan layanan e-payment. Kajian studi sebelumnya oleh Teoh et al. (2003) juga menemukan biaya keuangan turut berperan menentukan penggunaan layanan non tunai.

Berdasarkan argumen yang muncul dari hasil-hasil penelitian terdahulu itu, maka hipotesis kedua yang diajukan dalam penelitian ini dikaitkan dengan keputusan pengguna Gojek untuk menggunakan fasilitas e-payment berupa Gopay adalah:

H2 : Terdapat pengaruh parsial secara signifikan dari biaya keuangan yang dirasakan oleh pengguna Gojek terhadap keputusannya menggunakan Gopay.

Selain menguji pengaruh yang bersifat parsial, penelitian ini juga menganalisis pengaruh dari variabel-variabel bebas secara simultan terhadap variabel terikat. Dengan demikian, hipotesis ketiga yang diajukan dalam penelitian ini adalah:

H3 : Terdapat pengaruh simultan secara signifikan dari manfaat serta biaya keuangan yang dirasakan oleh pengguna Gojek terhadap keputusannya untuk menggunakan Gopay.

\section{Kerangka Pemikiran}

Penelitian ini berfokus pada analisis pengaruh dari variabel-variabel bebas yaitu manfaat dan biaya keuangan, terhadap sikap pengguna Gojek untuk menggunakan fasilitas layanan e-payment berupa Gopay. Berdasarkan sejumlah uraian sebelumnya atas fenomena yang dianalisis, maka kerangka pemikiran dari penelitian ini bisa ditunjukkan pada Gambar 1.

Gambar 1 menunjukkan jalur pengaruh antara variabel-variabel bebas terhadap variabel terikat. Garus lurus tidak terputus menyatakan pengaruh parsial dari masingmasing variabel bebas terhadap variabel terikat, yaitu jalur pengujian hipotesis pertama dan kedua. Sementara itu, garis putus-putus menyatakan pengaruh simultan dari semua variabel bebas terhadap variabel terikat, yaitu jalur pengujian hipotesis ketiga dari penelitian ini. 


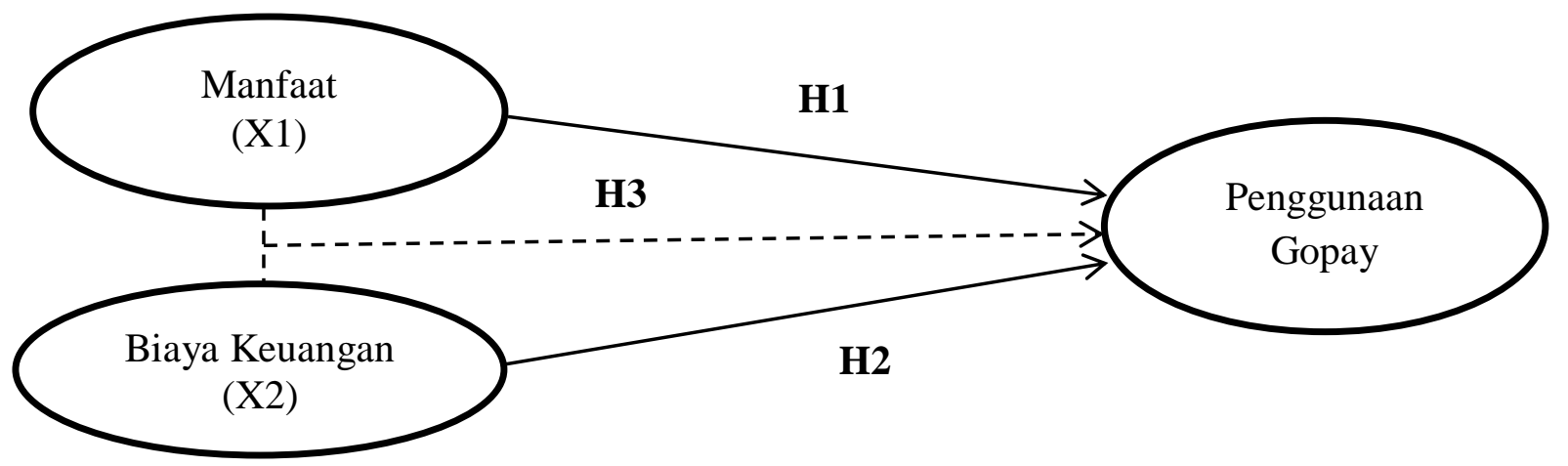

Gambar 1. Kerangka Penelitian

Sumber: Diolah peneliti, 2019.

\section{METODE PENELITIAN}

\section{Populasi dan Sampel}

Penelitian ini menelaah mengenai manfaat dan biaya finansial dalam mempengaruhi pelanggan Gojek menggunakan layanan Gopay. Subyek penelitian ini adalah civitas akademika Universitas Singaperbangsa (UNSIKA) Karawang - Jawa Barat yang jumlah tidak diketahui secara pasti.

Berikutnya, karena jumlah pengguna Gopay tidak diketahui dengan jelas, maka digunakan metode non-probability sampling. Penentuan sampel dilakukan dengan menggunakan teknik accidental sampling, yaitu teknik pengumpulan sampel secara tidak beraturan atau kebetulan, dimana jumlah sampel ditentukan sesuai dengan kebutuhan dalam penelitian ini (Sugiyono, 2012).

\section{Metode Pengumpulan Data}

Data yang digunakan adalah data numeric (Ghozali, 2016). Data dikumpulkan dari 118 responden, dengan cara mengisi kuisioner melalui google form yang disebarkan di grup WhatsApp yang ada di Unsika. Data penelitian ini diolah dengan metode analisa regresi berganda sederhana dengan menggunakan software SPSS ver. 19.

Berdasarkan Tabel 1, hasil uji validitas menunjukkan bahwa 11 item pertanyaan yang diberikan dalam kuesioner adalah valid. Item pertanyaan dianggap valid untuk digunakan apabila hasil uji menunjukan nilai Sig. (2tailed) lebih kecil dari 0,05 (Ghozali, 2016). Dengan demikian, instrumen penelitian ini dinyatakan memiliki item-item pertanyaan yang dinilai handal mengukur konstruk yang digunakan.

Lebih jauh, dari hasil uji reliabilitas menunjukkan nilai Cronbach's alpha untuk setiap item pertanyaan yang diajukan menunjukkan nilai antara 0,674 hingga 0,767. Karena nilai yang diperoleh tersebut masih diatas nilai 0,6 , maka hasil ini menyatakan bahwa item-item pertanyaan yang digunakan dalam kuesioner sebagai instrument penelitian ini adalah reliable (Ghozali, 2016).

\section{Metode Analisis Data}

Metode analisa data yang diaplikasikan pada penelitian ini meliputi beberapa tahapan. Tahap awal dimulai dengan uji asumsi klasik terdiri dari uji normalitas, uji heteroskedastisitas, serta uji multikoliniearitas.

Tahap berikutnya adalah analisa regresi linier berganda. Dengan melakukan analisa regeresi ini dapat diidentifikasi dampak atau pengaruh dari masing-masing variabel bebas yang terdiri dari manfaat (X1) dan biaya finansial (X2), terhadap variabel terikat yaitu layanan Gopay (Y). Tahap akhir dilakukan pengujian atas hipotesis penelitian baik untuk jalur pengaruh secara parsial maupun secara simultan. 
Tabel 1. Hasil Uji Validitas dan Reliabilitas

\begin{tabular}{llcc}
\hline No. & Item Pertanyaan & Nilai Sig. (2-tailed) & Nilai Cronbach's Alpha \\
\hline \multicolumn{2}{l}{ Manfaat (X1) } & & \\
1. Benefit 1 & 0,000 & \\
2. Benefit 2 & 0,000 & \\
3. Benefit 3 & 0,003 & 0,713 \\
4. Benefit 4 & 0,001 & \\
5. Benefit 5 & 0,002 & \\
\hline
\end{tabular}

Biaya Keuangan (X2)
6. Financial Costs 1
0,003
7. Financial Costs 2
0,000
8. Financial Costs 3
0,001
0,767
9. Financial Costs 4
0,001

Penggunaan Gopay (Y)

10. Gopay 1

0,000

11. Gopay 2

0,000

Sumber: Data primer diolah, 2019.

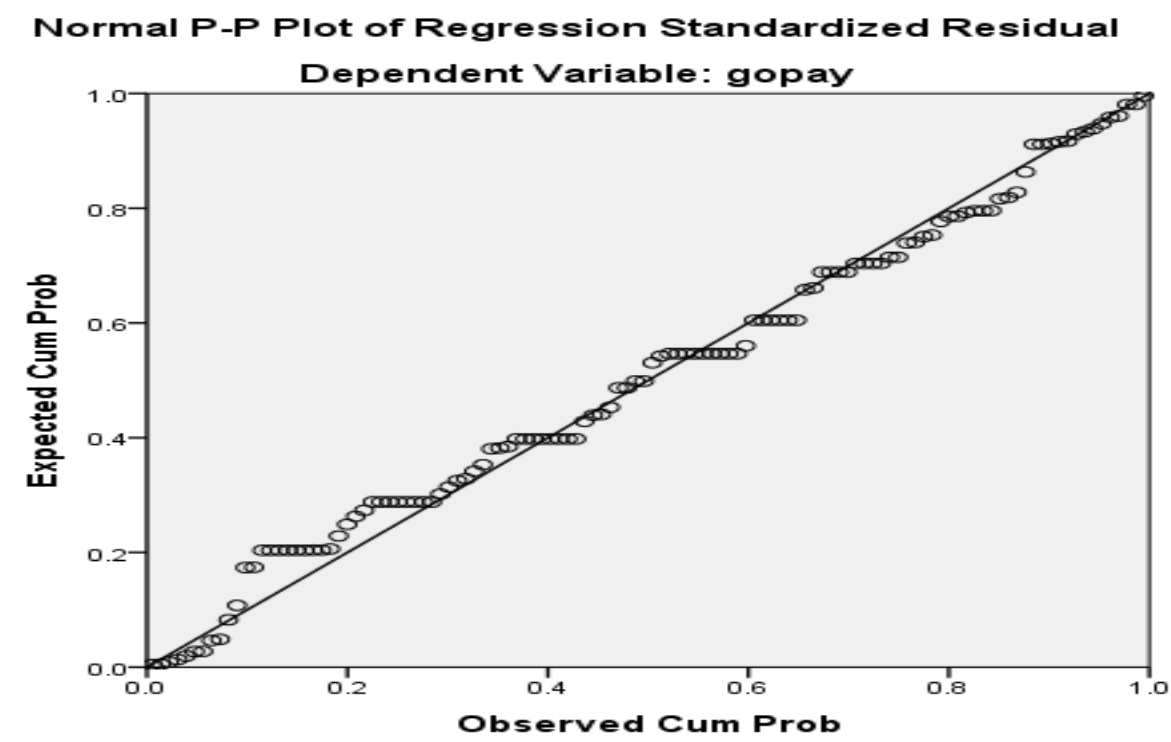

Gambar 2. Hasil Uji Normalitas

Sumber: Data primer diolah, 2019.

\section{HASIL ANALISIS}

\section{Hasil Uji Asumsi Klasik}

Tahap pertama dalam proses analisis data adalah melakukan uji asumsi klasik untuk memastikan kehandalan dari model regresi berganda yang diperoleh nentinya. Uji asumsi klasik dilakukan untuk melihat indikasi terjadinya persoalan-persoalan normalitas, heteroskedastisitas, dan multikolinearitas pada tahap analisis regresi linier berganda yang dilaksanakan. 
Berdasarkan Gambar 1 ditunjukkan hasil dari grafik normal plot bahwa terlihat jelas model regresi ini telah memenuhi asumsi normalitas. Grafik pada Gambar 1 mengidentifikasi bahwa terlihat jelas titik-titik yang menyebar di sekitar garis diagonal dan searah dengan garis diagonal. Berdasarkan hasil tersebut maka bisa dinyatakan bahwa model regresi berganda yang digunakan dalam penelitian ini telah memenuhi asumsi normalitas.

Selanjutnya, berdasarkan grafik Scatterplot yang ditunjukkan dalam Gambar 2 tampak bahwa titik-titik menyebar secara acak diatas dan dibawah angka nol (0) pada sumbu Y, bisa dipastikan tidak terjadi persoalan heteroskedistisitas. Dengan demi- kian, model regresi yang digunakan dalam penelitian ini bisa digunakan melakukan prediksi bagaimana pelanggan gojek memilih menggunakan Gopay berdasarkan variabelvariabel manfaat dan biaya keuangan.

Untuk mengantisipasi persoalan multikolinieritas, maka dilakukan uji terhadap data untuk melihat ada atau tidak indikasi multikolinieritas pada model regresi dari penelitian ini. Berdasarkan hasil yang terangkum dalam Tabel 2 teridentifikasi bahwa hasil perhitungan nilai Tolerance menunjukkan tidak ada variabel independen yang mempunyai nilai Tolerance kurang dari 0,1 . Hal ini berarti tidak ada kolerasi antar variabel independen (Ghozali, 2016).

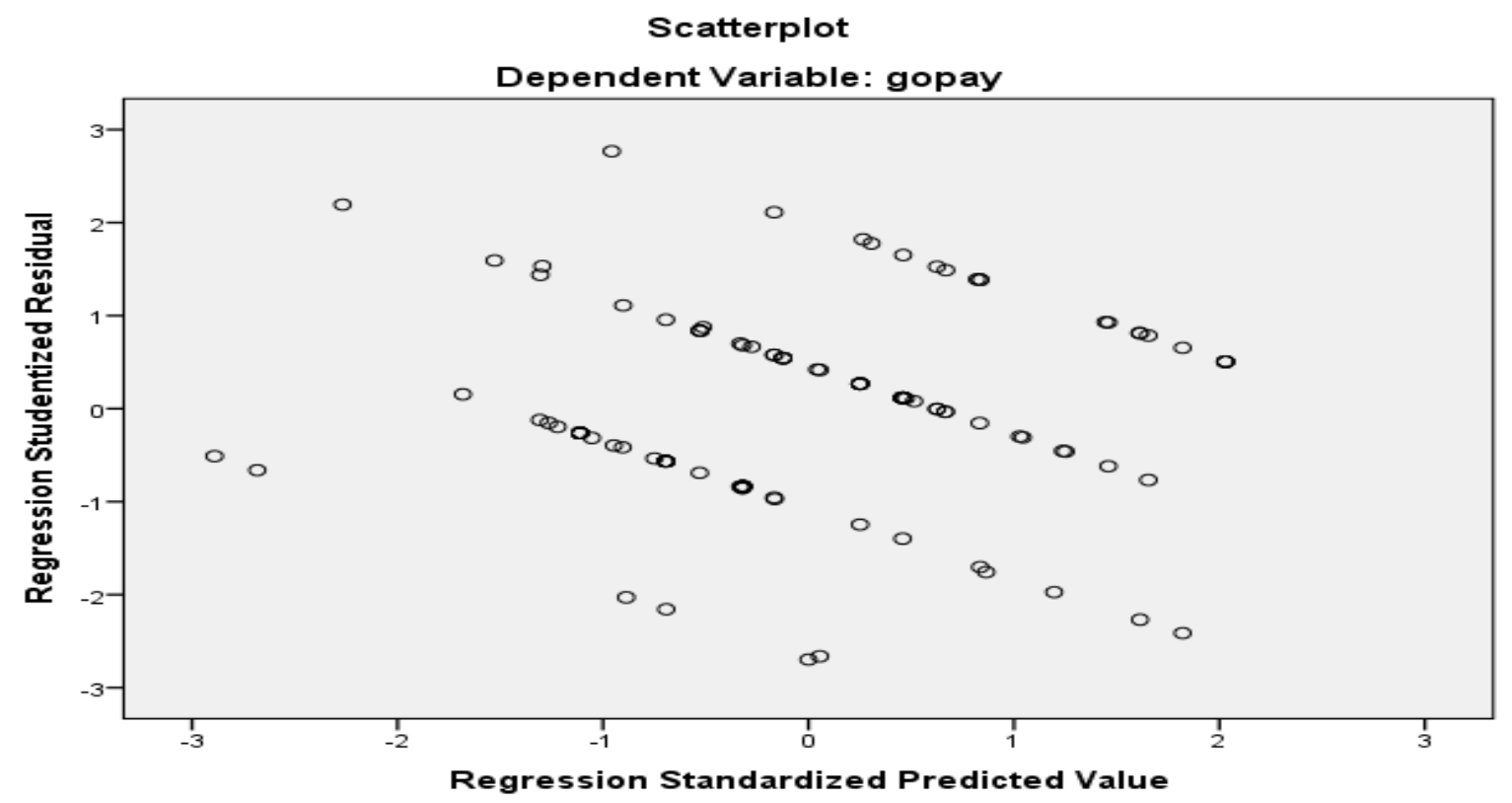

Gambar 2. Hasil Uji Heteroskedastisitas

Sumber: Data primer diolah, 2019.

Tabel 2. Hasil Uji Multikolinearitas

\begin{tabular}{cccc}
\hline \multicolumn{1}{c}{ Variabel } & Tolerance & VIF & Hasil \\
\hline Manfaat & 0,716 & 1,396 & Tidak Ada \\
Biaya Keuangan & 0,838 & 1,194 & $\begin{array}{c}\text { Multikolinearitas } \\
\text { Tidak Ada } \\
\text { Multikolinearitas }\end{array}$ \\
\hline
\end{tabular}

Sumber: Data primer diolah, 2019. 
Hasil perhitungan nilai Variance Inflation Factor (VIF) juga menunjukkan hal yang sama, yaitu tidak ada variabel independen yang memiliki nilai VIF lebih besar dari 10. Dengan demikian dapat dinyatakan bahwa tidak terdapat persoalan multikolinieritas antar variabel independen di dalam model regresi dalam penelitian ini (Ghozali, 2016).

\section{Analisis Deskriptif}

Responden dari penelitian ini adalah sivitas Universitas Singaperbangsa Karawang (Unsika), Jawa Barat. Kuisioner dibuat dengan menggunakan google form, dalam bentuk link yang disebarkan di berbagai grup WhatsApp yang ada di Unsika. Sampel yang diperoleh adalah 118 responden dengan kelayakan, dan berkesesuaian dengan persyaratan uji statistika yang diterapkan dengan menggunakan SPSS.

Analisa statistik deskriptif bertujuan untuk mengidentifikasi jenis kelamin dan usia responden. Berdasarkan Tabel 3 diperoleh hasil statistik bernilai mean (rata-rata) sebesar
1,6 dan nilai standar deviasi sebesar 0,48 untuk indikator jenis kelamin. Hasil ini bermakna jumlah responden berdasarkan jenis kelamin bahwa perempuan diidentifikasi lebih dominan dibandingkan pria.

Selanjutnya, berdasarkan indikator usia diperoleh nilai mean sebesar 1,23 dengan nilai standar deviasi sebesar 0,62. Hasil ini memberi informasi bahwa dari seluruh responden penelitian ini, lebih banyak daei mereka yang memiliki usia antara 18 tahun sampai 23 tahun. Kelompok usia termasuk rentang produktif dan memiliki banyak kegiatan yang dilakukan, sehingga untuk mendukung mobilitas mereka lebih banyak menggunakan transportasi seperti Gojek.

\section{Analisis Regresi Berganda}

Tabel 4 menyajikan hasil statistik untuk analisis regresi berganda. Hasil-hasil tersebut menunjukkan arah dan besaran pengaruh dari variabel-variabel bebas terhadap variabel terikat, serta derajat signifikansi dari masingmasing jalur pengaruh tersebut.

Tabel 3. Hasil Analisis Deskriptif

\begin{tabular}{lccccc}
\hline \multicolumn{1}{c}{ Indikator } & $\mathrm{N}$ & Min & Maks & Mean & Standar Deviasi \\
\hline Jenis Kelamin & 118 & 1 & 2 & 1,6 & 0,48 \\
Usia & 118 & 1 & 4 & 2,3 & 0,62 \\
\hline
\end{tabular}

Ket: - Jenis kelamin: (1) Pria; (2) Perempuan.

- Usia: (1) 18-25 th; (2) 26-33 th; (3) 34-41 th; (4) 42-50 th; (5) > 50 th.

Sumber: Data primer diolah, 2019.

Tabel 4. Hasil Analisis Regresi Berganda

\begin{tabular}{|c|c|c|c|}
\hline Variabel & B & $\mathrm{t}$ & Sig. $\mathrm{t}$ \\
\hline Manfaat & 0,200 & 2,158 & 0,000 \\
\hline Biaya Keuangan & 0,099 & 1,514 & 0,133 \\
\hline R-Adjusted Square & 0,326 & & \\
\hline Std. Error Estimated & 0,665 & & \\
\hline Sig. F & 0,000 & & \\
\hline
\end{tabular}

Sumber: Data primer diolah, 2019. 
Berdasarkan nilai koefisien regresi $B$ (Beta) yang ditunjukkan dalam Tabel 4 diidentifikasi bahwa baik manfaat $(\mathrm{X} 1=$ $0,200)$ serta biaya keuangan $(\mathrm{X} 2=0,099)$ merupakan variabel yang berpengaruh positif atas penggunaan Gopay oleh pengguna Gojek. Hal ini berarti apabila ada salah satu variabel bebas yang ditingkatkan penggunaannya dalam strategi perusahaan, maka semakin kuat keputusan pengguna Gojek untuk menggunakan Gopay sebagai fasilitas e-payment; atau sebaliknya, apabila ada salah satu variabel bebas yang menurun penggunaannya dalam strategi perusahaan, maka semakin turun keinginan pengguna Gojek untuk menggunakan Gopay.

Selanjutnya, berdasarkan perbandingan nilai $B$ maka dinyatakan bahwa manfaat (X1 $=0,200)$ merupakan variabel bebas yang paling besar pengaruhnya terhadap keputusan pengguna Gojek untuk menggunakan Gopay dibandingkan variabel biaya keuangan (X2 = 0,099). Hasil ini menunjukkan bahwa para pengguna Gojek memilih Gopay lebih karena alasan manfaat dari fasilitas e-payment tersebut dibandingkan faktor biaya keuangan. Dengan demikian, pihak pengelola Gojek dapat memberikan perhatian lebih besar atas unsur manfaat yang akan diterima para penggunanya di dalam penentuan strategi pemasaran dari Gopay.

\section{Hasil Uji Hipotesis}

Tabel 4 juga menunjukkan hasil uji hipotesis. Dalam penelitian terdapat tiga hipotesis yang diajukan, dimana hipotesis pertama (H1) dan kedua (H2) berkenaan dengan pengaruh parsial dari masing-masing variabel bebas atas variabel terikat menggunakan uji t (t-test); sementara hipotesis ketiga (H3) berkaitan dengan pengaruh simultan dari seluruh variabel bebas terhadap variabel terikat menggunakan uji $\mathrm{F}(F$-test $)$.
Berdasarkan Tabel 4 diidentifikasi variabel manfaat (X1) memiliki nilai Sig. $\mathrm{t}$ sebesar 0,000 atau lebih kecil dari nilai $\alpha$ $(0,05)$. Dengan demikian bisa dinyatakan bahwa manfaat memiliki pengaruh secara parsial yang signifikan terhadap keputusan pengguna Gojek untuk menggunakan Gopay, atau bahwa hipotesis pertama (H1) bisa diterima atau dibuktikan.

Berikutnya, berdasarkan Tabel 4 diidentifikasi variabel biaya keuangan (X2) memiliki nilai Sig. $t$ sebesar 0,133 atau lebih besar dari nilai $\alpha(0,05)$. Dengan demikian bisa dinyatakan bahwa biaya keuangan memiliki pengaruh secara parsial yang tidak signifikan terhadap keputusan pengguna Gojek untuk menggunakan Gopay, atau bahwa hipotesis kedua (H2) tidak bisa diterima atau tidak dibuktikan.

Hasil Uji F menunjukkan nilai yang diperoleh sebesar 0,000 atau lebih kecil dari nilai $\alpha(0,05)$. Berdasarkan hasil ini maka bisa dinyatakan bahwa manfaat dan biaya keuangan memiliki pengaruh secara simultan yang signifikan terhadap keputusan pengguna Gojek untuk menggunakan Gopay. Dengan demikian, hipotesis ketiga (H3) bisa diterima atau dibuktikan.

Lebih jauh, Tabel 4 menunjukkan nilai $R$-Square yang diperoleh dalam penelitian ni sebesar 0,326. Hasil koefisien determinasi tersebut menyatakan bahwa kemampuan dari manfaat serta biaya keuangan memiliki kemampuan dalam menjelaskan perubahanperubahan yang terjadi pada keputusan pengguna Gojek untuk menggunakan Gopay sebagai alat transaksi e-payment sebesar $32,6 \%$. Angka tersebut juga menunjukkan bahwa keputusan pengguna Gojek untuk menggunakan Gopay juga dipengaruhi pula oleh variabel-variabel lain yang tidak dicakup dalam persamaan regresi dari penelitian ini sebesar $67,4 \%$. 


\section{Pembahasan}

Hasil pertama yang diperoleh dari penelitian ini adalah bahwa manfaat terbukti memiliki pengaruh positif yang signifikan terhadap keputusan pengguna Gojek untuk menggunakan fasilitas e-payment berupa Gopay. Hasil penelitian ini mendukung buktibukti empiris milik sejumlah penelitian sebelumnya yang dilakukan Teoh et al. (2013) serta Pei et al. (2017), dan hingga saat ini belum ditemukan literasi yang memberikan bukti empiris berbeda dengan hasil penelitian ini. Lebih jauh, manfaat merupakan variabel yang paling besar pengaruhnya terhadap keputusan pengguna Gojek menggunakan layanan e-payment dalam hal ini Gopay.

Hasil kedua dalam penelitian ini adalah bahwa biaya keuangan terbukti memiliki pengaruh yang tidak signifikan terhadap keputusan pengguna Gojek untuk menggunakan fasilitas e-payment berupa Gopay. Hasil penelitian ini sejalan dengan bukti-bukti empiris yang diperoleh oleh sejumlah peneliti sebelumnya seperti Chellappa dan Pavlou (2002), Luarn dan Lin (2005) serta Tung dan Chang (2007). Hingga saat ini belum ditemukan literasi yang memberikan bukti empiris berbeda dengan hasil penelitian ini. Hasil ini memperkuat teori bahwa aspek biaya keuangan dalam layanan e-payment tidak berpengaruh terhadap keputusan para pengguna untuk menggunakan layanan $e$ payment berupa Gopay.

Terkait dengan hasil kedua tersebut, hal ini terjadi dimungkinkan karena para pengguna Gojek memandang layanan Gopay dibutuhkan karena manfaat yang dirasakan. Beberapa manfaat yang dinyatakan sebagai alasan utama bagi responden selaku pengguna Gojek untuk menggunakan layanan Gopay meliputi: (1) kemudahan dalam menggunakan Gopay; (2) kecepatan bertransaksi; (3) waktu yang digunakan lebih singkat dalam melaku- kan pembayaran; (4) tidak memerlukan ada kembalian; serta, (5) kenyamanan dalam bertransaksi.

Saat ini banyak tumbuh dan berkembang perusahaan yang menggunakan e-payment sebagai salah satu layanan untuk bertransaksi pembayaran. Hal ini juga yang menjadikan topik ini menjadi menarik untuk dianalisis. Implikasi dari penelitian ini adalah bisa digunakan sebagai salah satu rujukan pada studi-studi lanjutan terkait layanan $e$ payment seperti Gopay. Untuk riset di masa yang akan datang diharapkan menambah berbagai opsi variabel yang dinilai bisa membantu mempengaruhi keputusan pihak konsumen untuk mempergunakan layanan $e$ payment dalam proses transaksi.

\section{SIMPULAN}

Berdasarkan konstruk model yang diuji, perilaku pelanggan menggunakan layanan $e$ payment dalam hal ini Gopay terbukti secara signifikan dipengaruhi oleh pengaruh satu variabel independen yaitu manfaat. Berkenaan dengan unsur biaya keuangan, berdasarkan dari hasil peneliti ini diperoleh tidak berpengaruh secara signifikan terhadap layanan Gopay yang disediakan oleh Gojek.

Berkaitan dengan aspek metodologis, diharapkan penelitian ini bisa menjadi perbandingan untuk riset-riset selanjutnya yang melakukan topik serupa dengan menggunakan variabel yang sama ataupun berbeda. Dengan mencakup lebih banyak variabel penelitian seperti jenis kelamin, usia ataupun variabel-variabel lainnya baik sebagai variabel independen ataupun sebagai variabel intervening, upaya bisa menghasilkan referensi yang membantu perusahaan atau lembaga membangun jasa layanan e-payment dalam penyusunan strategi bersaingnya.

Penelitian ini disadari masih memiliki beberapa keterbatasan. Keterbatasan pertama adalah bahwa variabel-variabel yang dicakup 
dalam model penelitian ini untuk melihat fenomena pengguna Gopay relatif hanya dalam lingkup kecil yaitu di Unsika dengan segala kebiasaan dan budaya serta lokasinya berpengaruh terhadap hasil generalisasinya.

Keterbatasan kedua adalah bahwa berdasarkan hasil telaah yang memperbandingkan antara hasil penelitian ini dan hasil-hasil penelitian sebelumnya, terdapat beberapa variabel amatan yang bisa mempengaruhi keputusan konsumen menggunakan Gopay. Karenanya dinilai perlu dilakukan kajian lanjutan atas topik ini.

Limitas penelitian ini bisa merujuk pada aspek karakteristik budaya karena faktor geografis dan demografis merupakan sesuatu yang tidak bisa dihindari pada lokasi amatan yang berbeda. Meskipun penelitian ini memiliki keterbatasan yang berimplikasi pada ketidakmampuan kerangka model yang dirancang untuk dapat menjelaskan segala fenomena dan situasi, namun dengan melakukan prosedur pengujian yang akurat diharapkan tidak memitigasi level keyakinan akurasi atas model prediksi yang dihasilkan

\section{REFERENSI}

Chakravorti, S. 2003. Theory of Credit Card Networks: A Survey of the Literature. Review of Network Economics. 2(2): 50-68.

Chellappa, R.K. \& Pavlou, P. 2002. Perceived Information Security, Financial Liability and Consumer Trust in Electronic Commerce Transactions. Logistics Information Management. 15(5/6): 358-368.

Chou, Y.L. 2004. Understanding MCommerce Payment Systems through the Analytic Hierarchy Process. Journal of Business Research, 57(12): 14231430.

Davis, F.D. 1989. Perceived Usefulness, Perceived Ease of Use, and User Acceptance of Information Technology. MIS Quarterly. 13(3): 319-340.
Eastin, M. 2002. Diffusion of E-Commerce: An Analysis of the Adoption of Four Ecommerce Activities. Telematics and Informatics. 19(3): 251-267.

Flavián, C. \& Guinalíu, M. 2006. Consumer Trust, Perceived Security and Privacy Policy: Three Basic Elements of Loyalty to a Web Site. Industrial Management \& Data System. 106(5): 601-620.

Gerrard, P. \& Cunningham, J. 2003. The Diffusion of Internet Banking among Singapore Consumers. International Journal of Bank Marketing. 21(1): 1628.

Ghozali, I. 2016. Aplikasi Analisis Multivariate dengan Program SPSS. Semarang: Badan Penerbit Universitas Diponegoro.

Hsiao, C-H., Chang, J-J. \& Tang, K-Y. 2016. Exploring the Influential Factors in Continuance Usage of Mobile Social Apps: Satisfaction, Habit, and Customer Value Perspectives. Telematics and Informatics. 33(2): 342-355.

Luarn, P. \& Lin, H-H. 2005. Toward an Understanding of the Behavioral Intention to Use Mobile Banking. Computers in Human Behavior. 21(6): 873-891.

Mathieson, K., Peacock, E. \& Chin, W.W. 2001. Extending the Technology Acceptance Model: The Influence of Perceived User Resources. Data Base for Advances in Information Systems. 32(3): 86-112.

Pei, Y., Wang, S., Fan, J. \& Zhang, M. 2015. Empirical Study on the Impact of Perceived Benefit, Risk and Trust on EPayment Adoption: Comparing Quick Pay and Union Pay in China. Proceedings. 7th International Conference on Intelligent Human-Machine Systems and Cybernetics. 26-27 August, Hangzhou-China.

San-Martin, S. \& López-Catalán, B. 2013. How Can a Mobile Vendor Get Satisfied Customers?. Industrial Management and Data Systems. 113(2): 156-170. 
San-Martín, S., López-Catalán, B. \& RamónJerónimo, M. 2012. Factors Determining Firms' Perceived Performance of Mobile Commerce. Industrial Management and Data Systems. 112(6): 946-963.

Sugiyono. 2012. Metode Penelitian Bisnis. Bandung: Alfabeta.

Teoh, W.M-Y., Chong, S.C., Lin, B. \& Chua, J.W. 2013. Factors Affecting Consumers' Perception of Electronic Payment: An Empirical Analysis. Internet Research. 23(4): 465-485.

Tung, F-C. \& Chang, S-C. 2008. Nursing Students' Behavioral Intention to Use Online Courses: A Questionnaire Survey. International Journal of Nursing Studies. 45(9): 1299-1309.
Venkatesh, V., Morris, M.G., Davis, G.B. \& Davis, F.D. 2003. User Acceptance of Information Technology: Toward a Unified View. MIS Quarterly. 27(3): 425-478.

Venkatesh, V., Thong, J.Y.L. \& Xu, X. 2012. Consumer Acceptance and Use of Information Technology: Extending the Unified Theory of Acceptance and Use of Technology. MIS Quarterly. 36(1): 157-178.

Wang, Y-S., Wang, Y-M., Lin, H-H. dan Tang, T-I. 2003. Determinants of User Acceptance of Internet Banking: An Empirical Study. International Journal of Service Industry Management. 14(5): 501-519. 